\title{
Music Therapy: A Modalities to Consider During Rehabilitation of Neurological Patients
}

\author{
Pankaj Raj Nepal ${ }^{1}$ \\ ${ }^{1}$ Department of Neurosurgery, B and C Medical College Teaching Hospital and Research Center, Birtamode, \\ Jhapa, Nepal \\ Correspondence: \\ Dr. Pankaj Raj Nepal, FCPS \\ Editor-In-Chief: Eastern Green Neurosurgery \\ Deputy Medical Director, and Head of Department \\ Department of Neurosurgery, \\ $\mathrm{B}$ and C Medical College Teaching Hospital and Research Center, \\ Birtamode, Jhapa, Nepal \\ Email: pankajrajnepal@gmail.com
}

$\mathrm{T}$

The miracle of music can be pursued back to the prehistorical era where its connection with its healing power in emotional wellbeing can be understood. ${ }^{1,2}$ The neurochemical changes that occur after listening to music not only lessen the stress by reducing endorphin and cortisol level regulated by hypothalamic-pituitary-adrenal axis but also influences motivation and happiness by regulation of dopamine and opioids. ${ }^{3-6}$ Music remedy also seems to have an acquaintance with strengthening immunity set by serotonin and various peptide derivatives. ${ }^{6}$ Fukui and Toyoshima came up with the ideas of neurogenesis, regeneration, and repair of neurons that may be promoted by music therapy. ${ }^{7}$ Recently the various proof has been seen in different literature regarding the value of the various types of music therapy in neurological rehabilitation. A different aspect of sensory-motor function, speech and language function, and cognitive function has been shown to improve the various extent with the assistance of music therapy. ${ }^{8-10}$

Thaut MH et al have shown the role of neurological music therapy in the rehabilitation of sensory-motor function particularly in terms of mobilization, motor, power, and coordination, and meaningful use has been shown to improve with

1

Date submitted: $11 / 0$ 8/2020

Date accepted: 12/09/2020 neurological music therapy., ${ }^{9,10,11}$ Furthermore, cognitive functions like memory and various psychosocial expression also were improved with the therapy.

The neurological condition like multiple sclerosis and parkinsonism is a common neurological condition influencing different age group which gradually progress over time. In multiple sclerosis, the rhythmic auditory stimulation has some notable improvement in gait kinematic parameters like stride length, stride time, cadence, and gait speed of patients. ${ }^{12}$ Likewise, in patients with Parkinson's disease, a rhythmic auditory stimulation has shown a significant increase in step length and gait speed. ${ }^{13,14}$ The neural basis of rhythmic auditory stimulation seems to stimulate the supplementary motor area, pre-supplementary motor area, premotor cortex, basal ganglia, and cerebellum, which leads to muscle activation. ${ }^{15-18}$ The postural control and co-ordination with music therapy has been postulated by activating the vestibular system through the medial geniculate ganglia and auditory cortex in the temporal lobe. ${ }^{19}$

Traumatic brain injury is a pandemic subsequent to the expansion of high-speed motor vehicles. It appears to affect the huge group of populations throughout the world. The majority of the severely

egneuro Volume 02, Issue 03, 2020 
head-injured patient seems to have problems with various aspects of consciousness, psychological problems, social problems, motor function, and cognitive function. This enigma seems to last a very long span and despite various neurological and neurosurgical development, very little has been achieved for the restoration of these problems. The most accepted treatment during the recovery from head injury is neurological rehabilitation mainly with early mobilization and physiotherapy. The addition of music therapy has shown significant improvement in executive function, mental versatility, attention, and memory. ${ }^{11}$ It also unveiled a notable reduction in post-traumatic depression and anxiety. ${ }^{11}$

\section{Conclusion:}

The addition of music therapy during rehabilitation for various neurological conditions including traumatic brain injury shows an acceptable result.

\section{References:}

1. Shannon K. Neurologic music therapy: a scientific paradigm for clinical practice. Music and Medicine. 2010;2(2):78-84.

2. Thaut MH. Music in therapy and medicine: from social science to neuroscience. Rhythm, music, and the brain: Scientific foundations and clinical applications. 2005; 113:136

3. Koelsch S, Fuermetz J, Sack U, Bauer K, Hohenadel M, Wiegel M, Kaisers U, Heinke W. Effects of music listening on cortisol levels and propofol consumption during spinal anesthesia. Frontiers in psychology. 2011 Apr 5; 2:58.

4. Suda M, Morimoto K, Obata A, Koizumi H, Maki A. Emotional responses to music: towards scientific perspectives on music therapy. Neuroreport. 2008 Jan 8;19(1):75-8.

5. Khalfa S, Bella SD, Roy M, Peretz I, Lupien SJ. Effects of relaxing music on salivary cortisol level after psychological stress. ANNALS-NEW YORK ACADEMY OF SCIENCES. 2003 Nov 1; 999:374-6.

6. Levitin DJ, Chanda ML. The neurochemistry of music. Trends in Cognitive Sciences. 2013;17(4):179-93.

7. Fukui H, Toyoshima K. Music facilitate the neurogenesis, regeneration and repair of neurons. Medical hypotheses. 2008 Nov 1;71(5):765-9.

8. Clair AA, Pasiali V, LaGasse B. Neurologic music therapy. Introduction to approaches in music therapy. 2008; 153:172.

9. Thaut C, Stephan KM. Neurologic music therapy in sensorimotor rehabilitation. InThe Oxford Handbook of Music and the Brain 2005.
10. Thaut MH. Neurologic music therapy in cognitive rehabilitation. Rhythm, music and the brain. 2005:179201.

11. Thaut M, Gardiner J, Holmberg D, Horwitz J, Kent L, Andrews G, Donelan B, Mcintosh G. Neurologic music therapy improves executive function and emotional adjustment in traumatic brain injury rehabilitation. Annals of the New York Academy of Sciences. $2009 \mathrm{Jul}$ 1;1169(1):406-16.

12. Shahraki M, Sohrabi M, Torbati HT, Nikkhah K, NaeimiKia M. Effect of rhythmic auditory stimulation on gait kinematic parameters of patients with multiple sclerosis. Journal of medicine and life. 2017 Jan;10(1):33.

13. Rochester L, Nieuwboer A, Baker K, Hetherington V, Willems AM, Chavret F, Kwakkel G, Van Wegen E, Lim I, Jones D. The attentional cost of external rhythmical cues and their impact on gait in Parkinson's disease: effect of cue modality and task complexity. Journal of neural transmission. 2007 Oct 1;114(10):1243.

14. Rochester L, Baker K, Hetherington V, Jones D, Willems AM, Kwakkel G, Van Wegen E, Lim I, Nieuwboer A. Evidence for motor learning in Parkinson's disease: acquisition, automaticity and retention of cued gait performance after training with external rhythmical cues. Brain research. 2010 Mar 10; 1319:103-11.

15. Thaut MH, McIntosh GC, Rice RR. Rhythmic facilitation of gait training in hemiparetic stroke rehabilitation. Journal of the neurological sciences. 1997 Oct 22;151(2):207-12.

16. Bengtsson SL, Ullen F, Ehrsson HH, Hashimoto T, Kito T, Naito E, Forssberg H, Sadato N. Listening to rhythms activates motor and premotor cortices. cortex. 2009 Jan 1;45(1):62-71.

17. Chen JL, Penhune VB, Zatorre RJ. Listening to musical rhythms recruits motor regions of the brain. Cerebral cortex. 2008 Dec 1;18(12):2844-54.

18. Grahn JA, Brett M. Rhythm and beat perception in motor areas of the brain. Journal of cognitive neuroscience. 2007 May;19(5):893-906.

19. Horak FB. Clinical measurement of postural control in adults. Physical therapy. 1987 Dec 1;67(12):1881-5. 